\title{
MicroRNA-140 mediates RB tumor suppressor function to control stem cell-like activity through interleukin-6
}

\author{
Akiyo Yoshida ${ }^{1,2}$, Shunsuke Kitajima ${ }^{1,3}$, Fengkai Li $^{1}$, Chaoyang Cheng ${ }^{4}$, Yujiro \\ Takegami ${ }^{4}$, Susumu Kohno ${ }^{1}$, Yuan Song Wan ${ }^{1}$, Naoyuki Hayashi ${ }^{1,5}$, Hayato Muranaka ${ }^{1}$, \\ Yuuki Nishimoto ${ }^{1}$, Naoko Nagatani ${ }^{1}$, Takumi Nishiuchi ${ }^{6}$, Tran C Thai ${ }^{3}$, Sawako Suzuki ${ }^{7}$, \\ Shinji Nakao ${ }^{2}$, Tomoaki Tanaka7, Osamu Hirose ${ }^{8}$, David A. Barbie $^{3}$, Chiaki Takahashi ${ }^{1}$ \\ ${ }^{1}$ Division of Oncology and Molecular Biology, Cancer Research Institute, Kanazawa University, Kanazawa, Ishikawa \\ 920-1192, Japan \\ ${ }^{2}$ Deperment of Cellular Transplantation Biology, Graduate School of Medical Science, Kanazawa University, Kanazawa, \\ Ishikawa 920-8641, Japan \\ ${ }^{3}$ Department of Medical Oncology, Dana-Farber Cancer Institute, Boston, MA02215, USA \\ ${ }^{4}$ DNAFORM Precision Gene Technologies, Yokohama, Kanagawa, 230-0046, Japan \\ ${ }^{5}$ Department of Health and Nutrition, Faculty of Human Health Science, Kanazawa Gakuin University, Kanazawa, Ishikawa, \\ 920-1302, Japan \\ ${ }^{6}$ Division of Functional Genomics, Advanced Science Research Center, Kanazawa University, Kanazawa, Ishikawa 920-0934, \\ Japan \\ ${ }^{7}$ Deperment of Clinical Cell Biology and Medicine, Graduate School of Medicine, Chiba University, Chiba, Chiba 260-8670 \\ Japan \\ ${ }^{8}$ Division of Electrical Engineering and Computer Science, Graduate School of Natural Science and Technology, Kanazawa \\ University, Kanazawa, Ishikawa 920-1192, Japan \\ Correspondence to: Chiaki Takahashi, email: chtakaha@staff.kanazawa-u,.ac.jp \\ Shunsuke Kitajima, email: shunsuke_kitajima@dfci.harvard.edu
}

Keywords: cancer, cancer stem cells, RB, mir-140, interleukin-6

Received: June 29, $2016 \quad$ Accepted: January 03, $2017 \quad$ Published: January 16, 2017

\section{ABSTRACT}

We established an in vitro cell culture system to determine novel activities of the retinoblastoma ( $\mathrm{Rb}$ ) protein during tumor progression. $\mathrm{Rb}$ depletion in p53-null mouse-derived soft tissue sarcoma cells induced a spherogenic phenotype. Cells retrieved from $\mathbf{R b}$-depleted spheres exhibited slower proliferation and less efficient BrdU incorporation, however, much higher spherogenic activity and aggressive behavior. We discovered six miRNAs, including mmu-miR-18a, -25, -29b, -140, -337 , and -1839 , whose expression levels correlated tightly with the Rb status and spherogenic activity. Among these, mmu-miR-140 appeared to be positively controlled by $\mathbf{R b}$ and to antagonize the effect of Rb depletion on spherogenesis and tumorigenesis. Furthermore, among genes potentially targeted by mmu-miR-140, Il-6 was upregulated by Rb depletion and downregulated by mmu-mir-140 overexpression. Altogether, we demonstrate the possibility that mmu-mir-140 mediates the Rb function to downregulate Il- 6 by targeting its 3'-untranslated region. Finally, we detected the same relationship among RB, hsa-miR-140 and IL-6 in a human breast cancer cell line MCF-7. Because IL- 6 is a critical modulator of malignant features of cancer cells and the RB pathway is impaired in the majority of cancers, hsa-miR-140 might be a promising therapeutic tool that disrupts linkage between tumor suppressor inactivation and pro-inflammatory cytokine response. 


\section{INTRODUCTION}

MicroRNAs (miRNAs) are non-coding 18 to 25 base pair ribonucleotides that post-transcriptionally downregulate proteins by binding to a complementary sequence in the $3^{\prime}$-untranslated region (3'UTR) of target gene mRNA $[1,2]$. Recently, miRNAs have emerged as critical modifiers of malignant phenotypes in several cancers [3-5]. Extensive downregulation of miRNAs was observed in human tumor cells relative to normal tissues $[6,7]$. Lower expression of components mediating miRNA biosynthesis such as DROSHA and DICER1 was correlated with poor prognosis in ovarian cancers and neuroblastomas $[8,9]$. These findings indicate tumorsuppressive functions that are shared by a wide variety of miRNAs. Indeed, Dicerl knockout mice, in which miRNA expression is globally repressed, exhibit a tumor-prone phenotype $[10,11]$, even though some miRNAs such as $m i R-21$ have oncogenic functions [12].

The tumor-suppressive functions of miRNAs are attained primarily by their ability to interfere with the translation of oncogenic mRNAs. For example, the $m i R$-200 family antagonizes the epithelial-mesenchymal transition (EMT) associated with cancer metastasis by downregulating transcriptional suppressors of E-cadherin, such as ZEB1 and ZEB2 [13]. Furthermore, let-7, miR-15a, $m i R-31, m i R-34, m i R-205$ and others were demonstrated to suppress Ras, Myc, Bcl2, Notch, E2F1 or CyclinD1 [14], suggesting a tumor-suppressive activity for these miRNAs. However, exactly how these tumor-suppressive miRNAs are regulated during tumor progression remains poorly defined.

The tumor suppressor protein retinoblastoma (RB) is genetically or functionally inactivated in many human cancers, and exerts its tumor-suppressive functions through physical interactions with various effector molecules including E2F transcription factors, tissuespecific transcription factors, $\mathrm{LxCxE}$ motif-containing chromatin modifiers, and the E3 ubiquitin protein ligase SKP2. Due to the large variation in its binding partners, the RB transcriptional complex can either promote or repress expression of its target genes [15].

In this study, we employed an in vitro model of cancer progression wherein $\mathrm{Rb}$ inactivation enhances stem cell-like activities. We identified miRNAs whose levels differ in close association with the RB status and stem cell-like activities. This unveiled a relationship between RB and miR-140; depletion of RB downregulates miR-140. The mir-140 has been implicated in the suppression of hepatocellular carcinoma, non-small cell lung cancer, colon cancer, breast cancer and ovarian cancer through the inhibition of growth factor signaling [16-20]. We further identified IL-6 gene as a possible direct target of mir-140. Rb depletion indeed upregulated IL-6 expression, which was antagonized by overexpression of mir-140. Therefore, this study proposes that $\mathrm{Rb}$ downregulates IL-6 through upregulation of mir-140.

\section{RESULTS}

\section{Il-6 mRNA upregulation is associated with an undifferentiated state following $R \mathbf{b}$ inactivation}

Previously, we demonstrated that a p53-null background facilitates cells to acquire undifferentiated phenotypes including increased self-renewal upon RB inactivation $[21,22]$. To determine the RB-inactivation signature in the context of gaining self-renewal activity in a $p 53$-null genetic background, we employed a soft tissue sarcoma model. $p 53^{---}$mice in a C57BL/6 background developed soft tissue-derived sarcoma with a frequency of approximately $20 \%$. Cells derived from these tumors were readily adaptable to 2-dimensional (2D) culture, and appeared to be poorly spherogenic when cultivated in serum-free medium supplemented with EGF, bFGF and B-27 in a non-adherent dish type. However, upon Rb depletion, these cells efficiently formed small spheres up to day 14 in sphere culture (Figure 1A-1E), suggesting enhanced self-renewal activity in Rb depleted cells.

Next we recovered viable cells from the spheres derived from $\mathrm{Rb}$-depleted cells. Spheres with surface areas $>5,000 \mu \mathrm{m}^{2}$ and ratios of the longest/shortest diameter $(\mathrm{L} / \mathrm{S}$ ratio $)<1.5$ were manually picked, disaggregated with a cell strainer, and plated onto a 2D culture dish (Figure 1A and Supplementary Figure 1A). We referred to these cells as "Rb-depleted secondary cells" and conducted all analysis of these cells before they reached passage 4. "Control secondary cells" were derived from cells surviving 3D culture conditions for sphere formation, although these cells did not form visible spheres.

Both control and Rb-depleted secondary cells re-adapted well to 2D culture conditions. However, as compared to control and other primary cells, Rb-depleted secondary cells exhibited flattened cell shapes and slower growth (Figure 1D). In agreement, Rb-depleted secondary cells showed decreased cyclin D1 expression (Figure 1C) and less efficient BrdU incorporation (Supplementary Figure 1B). However, Rb-depleted, sphere-derived secondary cells exhibited the highest spherogenic activity, resistance to doxorubicin treatment and metastatic activity in mice when compared to the three other types of cells (Figure 1E and 1F, and Supplementary Figure 1C).

We analyzed all four types of cells by RNA sequencing. We found that the well-established cancer stem cell marker Aldh1a3 was highly expressed in $\mathrm{Rb}$-depleted secondary cells, strongly implicating the enrichment of stem cell-like cells in this cell population (Figure 1G). In addition to Aldhla3, we found that Hgf, Vegfa, Il-6, Cxcll and Kit were highly expressed 
in Rb-depleted secondary cells (Figure 1G). Of note, except for Kit, all these genes were upregulated in $\mathrm{Rb}$ depleted primary cells as well, implicating a genetic interaction between $\mathrm{Rb}$ and these genes. Additionally, we observed that $\mathrm{Rb}$ depletion suppressed smooth muscle actin 2 (Acta2) expression (Figure 1G). Subcutaneous tumors derived from $\mathrm{Rb}$-depleted cells transplanted into C57BL/6 mice also showed increased Hgf, Il-6, and Cxcll expression and decreased Acta2 expression (Figure 1H). Collectively, these findings indicate that $\mathrm{Rb}$ depletion induces upregulation of specific growth factors and cytokines, and dedifferentiation in p53-null soft tissue sarcoma cells.

\section{miRNA expression profiling identifies mmu- miR-140 downregulation in conjunction with this $\mathbf{R b}$-inactivated undifferentiated state}

We next determined the Rb-inactivation signature of miRNA in addition to mRNA. To this end, we performed a miRNA array assay with control primary cells and Rbdepleted primary and secondary cells. We conducted
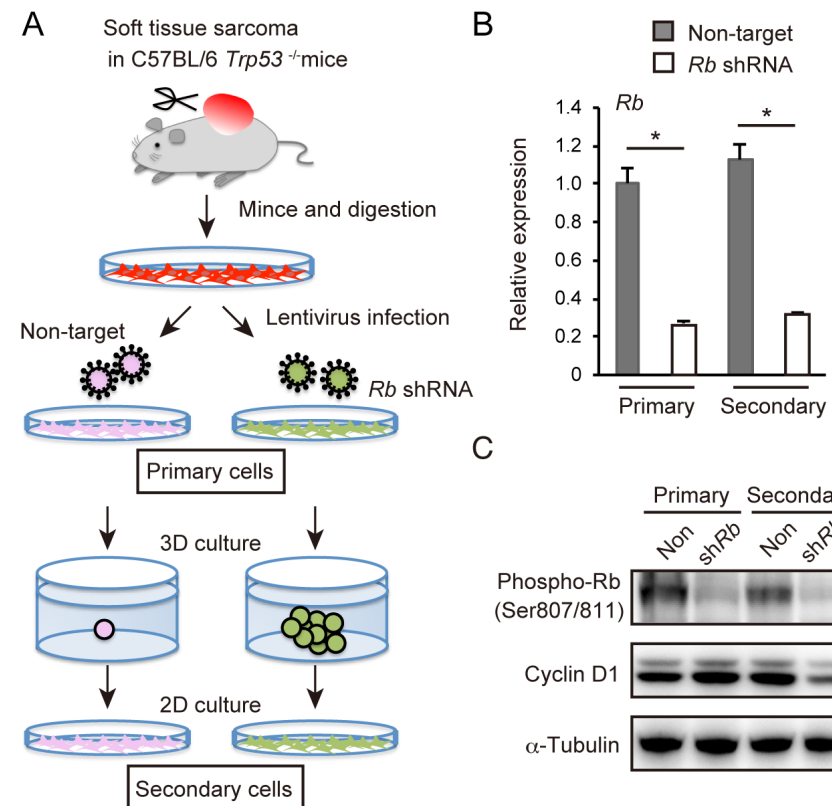

C

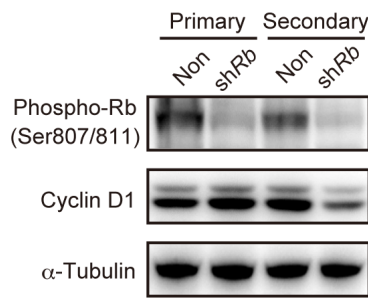

$\mathrm{F}$

Non-target $\square R b$ shRNA

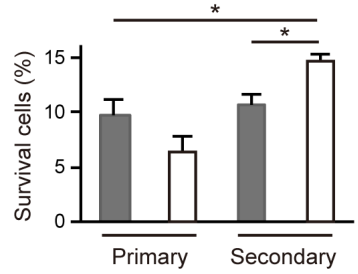

G
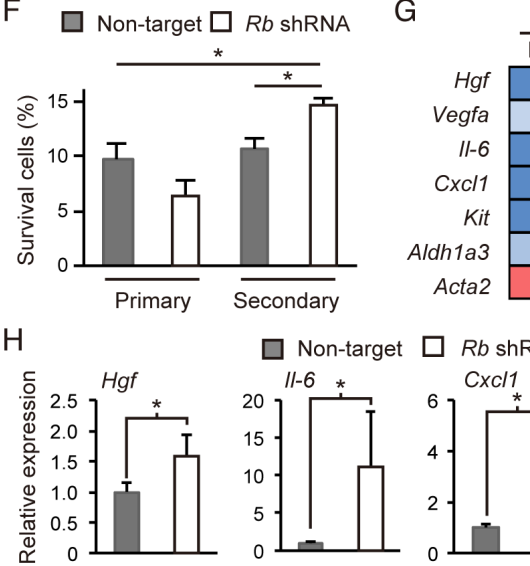

$\square$ Non-target
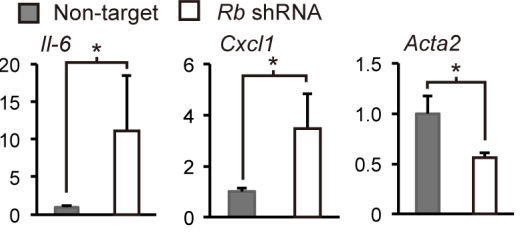
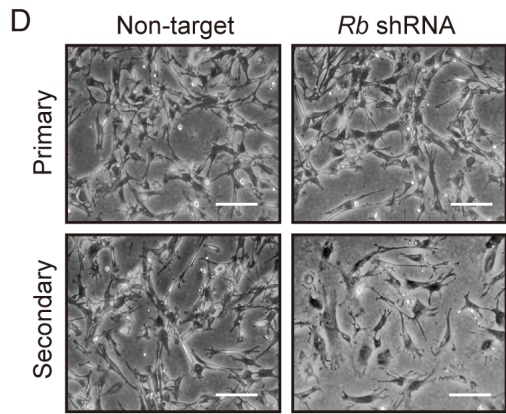

E

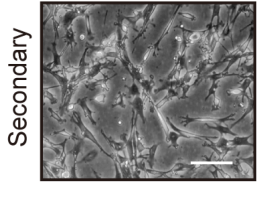

$R b$ ShRNA
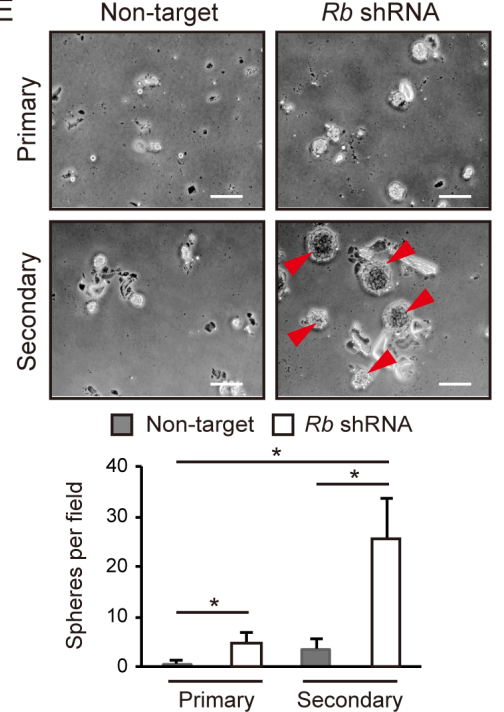

Figure 1: Analysis of Rb depletion-induced spherogenic cells. (A) Protocol for the preparation of Rb depletion-induced spherogenic cells (Rb-depleted secondary cells) from p53-null soft tissue sarcoma cells. (B) RT-qPCR of Rb in $p 53$-null sarcoma cells transduced with the indicated vector. $N=3$. Columns represent the mean and standard deviation (S.D.) unless otherwise indicated. (C) Immunoblot (IB) of the indicated proteins in p53-null soft tissue sarcoma cells transduced with the indicated vector. (D) Phasecontrast images of $p 53$-null soft tissue sarcoma cells grown in monolayer culture transduced with the indicated vector. Scale bar: $200 \mu \mathrm{m}$. (E) Spheres (arrowheads) derived from p53-null soft tissue sarcoma cells transduced with the indicated vector (upper). Scale bar: $200 \mu \mathrm{m}$. Sphere numbers per field (lower). $N=3$. (F) Cell survival rates for $p 53$-null soft tissue sarcoma cells transduced with the indicated vector after treatment with $250 \mathrm{nM}$ doxorubicin for 72 hours. $N=3$. (G) Heat map of rpkm values of the indicated genes in $p 53$-null soft tissue sarcoma cells transduced with the indicated vector. $(\mathbf{H}) 1 \times 10^{5}$ cells transduced with the indicated vector were injected into C57BL/6 mice. RT-qPCR results of the indicated genes in tumors derived from implanted $p 53$-null soft tissue sarcoma cells transduced with the indicated shRNA are shown (day 24). $N=3$. 
principal component analysis (PCA) using a variancecovariance matrix. The cumulative contribution rate of the first (PC1) and second principal components (PC2) was $77 \%$. The samples were divided into primary and secondary cells by the axis of the PC1 score, and control and $\mathrm{Rb}$-depleted cells by the axis of the PC2 score (Figure 2A). Then we conducted an unsupervised hierarchical clustering analysis using Ward's method. The samples were successfully divided into clusters of primary and secondary cells. The primary cell clusters were also subdivided into clusters of control and Rb-depleted cells (Figure 2B). Based on these results, we concluded that the obtained miRNA expression profiles were well organized and specific in each cell type.

Using these miRNA expression profiles, we identified miRNAs whose expression level correlate with $\mathrm{Rb}$ status and stem cell-like features simultaneously. At first, we conducted one-way analysis of variance (ANOVA) with 252 miRNAs. The resultant 37 miRNAs with adjusted $p$ values $<0.1$ were subjected to Dunnett's test using non-target cells as control, and we then identified six miRNAs (mmu-miR-18a, -25, -29b, -140, -337, and -1839 ) with adjusted $p$ values $<0.05$ (Figure 2C). Among these six miRNAs, mmu-miR-140 and -337 appeared to be downregulated by $\mathrm{Rb}$ deletion in both $2 \mathrm{D}$-cultured and sphere-derived cells. Of these two miRNAs, mmumiR-140 exhibited more robust fold change. In addition, mmu-miR-140 sequence was conserved between mouse and human (Figure 2C). For these reasons, our subsequent studies focused on mmu-miR-140.

We validated the expression of mmu-miR140-5p (miR-140) and mmu-miR-140-3p (miR-140*) in the three cell types by reverse transcription-quantitative PCR (RT-qPCR) (Figure 2D and Supplementary Figure 2A). These results indicated that both forms of mmu-mir-140 are downregulated by $\mathrm{Rb}$ depletion in primary cells; this downregulation was more robust in Rb-depleted secondary cells (Figure 2D). In addition, we demonstrated that mmu-miR-140 downregulation induced by $\mathrm{Rb}$ depletion was antagonized by $\mathrm{RB}$ overexpression (Figure 2E), suggesting that Rb upregulates mmu-miR-140 expression.

\section{mmu-mir-140 antagonizes malignant features induced by $\mathbf{R b}$ depletion}

Since hsa-mir-140, the human orthologue of $m m u$ mir-140, has been implicated in tumor suppression [16-20], we investigated whether mmu-mir-140 mediates Rb function to suppress tumor development in the soft tissue sarcoma model. We transduced a lentiviral vector expressing $\mathrm{mmu-}$ mir-140 (a precursor of mmu-miR-140 and mmu-miR-140*) or scrambled sequence into control or Rb-depleted cells. We verified mmu-miR-140 expression in transduced cells by RT-qPCR (Figure 3A). We found that mmu-mir-140 overexpression did not induce apoptosis but attenuated the cell growth of both control and $\mathrm{Rb}$ depleted cells in 2D culture (Figure 3B and Supplementary Figure 3A and 3B). The degree of growth suppression was modest; however, mmu-mir-140 overexpression significantly antagonized sphere formation induced by $\mathrm{Rb}$ depletion (Figure $3 \mathrm{C}$ ). In addition, mmu-mir-140 overexpression antagonized in vivo tumorigenicity enhanced by Rb depletion (Figure 3D). These findings indicate the possibility that mmu-mir-140 mediates the function of $\mathrm{Rb}$ to suppress tumor development.

\section{Identification of genes regulated by $\mathrm{Rb}$ in a mmu-mir-140-dependent manner}

To further explore the possibility that mir-140 may mediate the tumor-suppressive function of RB, we investigated genes regulated by $\mathrm{Rb}$ in a mir-140-dependent manner. To this end, we surveyed genes potentially targeted by mmu-mir-140 among genes that were upregulated by $\mathrm{Rb}$ depletion. We searched for genes those predicted to be targeted by mmu-mir-140 at microRNA.org. This search was made in the list of candidate genes identified by RNAsequence as upregulated upon $\mathrm{Rb}$ depletion. We identified genes that had less than 0.5 mirSVR score to mmu-mir-140 as candidate genes regulated by $\mathrm{Rb}$ in a mir-140 dependent manner (Table 1). In addition, we performed transcriptome and gene ontology (GO)-enrichment analysis in Rb-depleted and/or mmu-mir-140-overexpressed soft tissue sarcoma cells by cap analysis gene expression (CAGE). The gene set induced by $\mathrm{Rb}$ depletion in a mir-140-dependent manner (induced by $\mathrm{Rb}$ depletion and suppressed by mir-140 overexpression) was enriched by genes encoding soluble factors mediating immune responses and growth stimuli (Figure 4A, Supplementary Tables 1 and 2), such as Il-6, Il-11, Hgf, Vegfa, Wnt5a, Fgf10 and Serping1 (Figure 4B). The 3'UTR regions in these genes appeared to have highly possible mir-140 target sequence (Figure 4C).

\section{mmu-mir-140 mediates $\mathrm{Rb}$ function to control Il-6 expression}

We then focused on Il- 6 because it was the most upregulated gene following $\mathrm{Rb}$ depletion (Table 1). Il-6 upregulation induced by $\mathrm{Rb}$ depletion was significantly antagonized by $\mathrm{RB}$ reconstitution (Figure 5A). In addition, Il-6 has a mir-140 target sequence in the $3^{\prime} \mathrm{UTR}$ of both the human and mouse gene. Indeed, mmu-mir-140 overexpression significantly antagonized upregulation of $\mathrm{Il}-6$ abundance induced by $\mathrm{Rb}$ depletion (Figure 5B). On the other hand, mmu-mir-140 depletion in Rb intact sarcoma cells was not sufficient to induce robust Il-6 upregulation or increased sphere forming activity (data not shown), suggesting that mmu-mir-140 mediates $\mathrm{Rb}$ function to suppress Il-6 and sphere formation in a limited degree.

To determine whether the Il-6 mRNA translation is directly suppressed by mmu-mir-140, we constructed 
luciferase reporter vectors carrying either a wild-type mouse Il-6-3'UTR (mIl-6-3'UTR-WT) or a mutated target sequence ( $\left.m I l-6-3^{\prime} U T R-M u t\right)$ (Figure $5 \mathrm{C}$ ). We found that mmu-mir-140 overexpression significantly repressed the activity of mIl-6-3'UTR-WT but not mIl-6-3'UTRMut (Figure 5D). Moreover, addition of recombinant mouse Il-6 significantly blocked the inhibition of spherogenesis caused by mmu-mir-140 overexpression in a concentration-dependent manner (Figure 5E). These data implicate that mmu-mir-140 suppresses IL- 6 translation by binding to 3'UTR of $I L-6$ mRNA, therefore may mediate $\mathrm{Rb}$ function to suppress tumor progression.

\section{hsa-mir-140 suppressed $I L-6$ upregulation following RB depletion in human breast cancer cells}

To examine whether the hsa-mir-140-IL-6 axis are involved in malignant phenotype induced by $\mathrm{RB}$ inactivation in human cancers, we employed MCF-7, a luminal-type
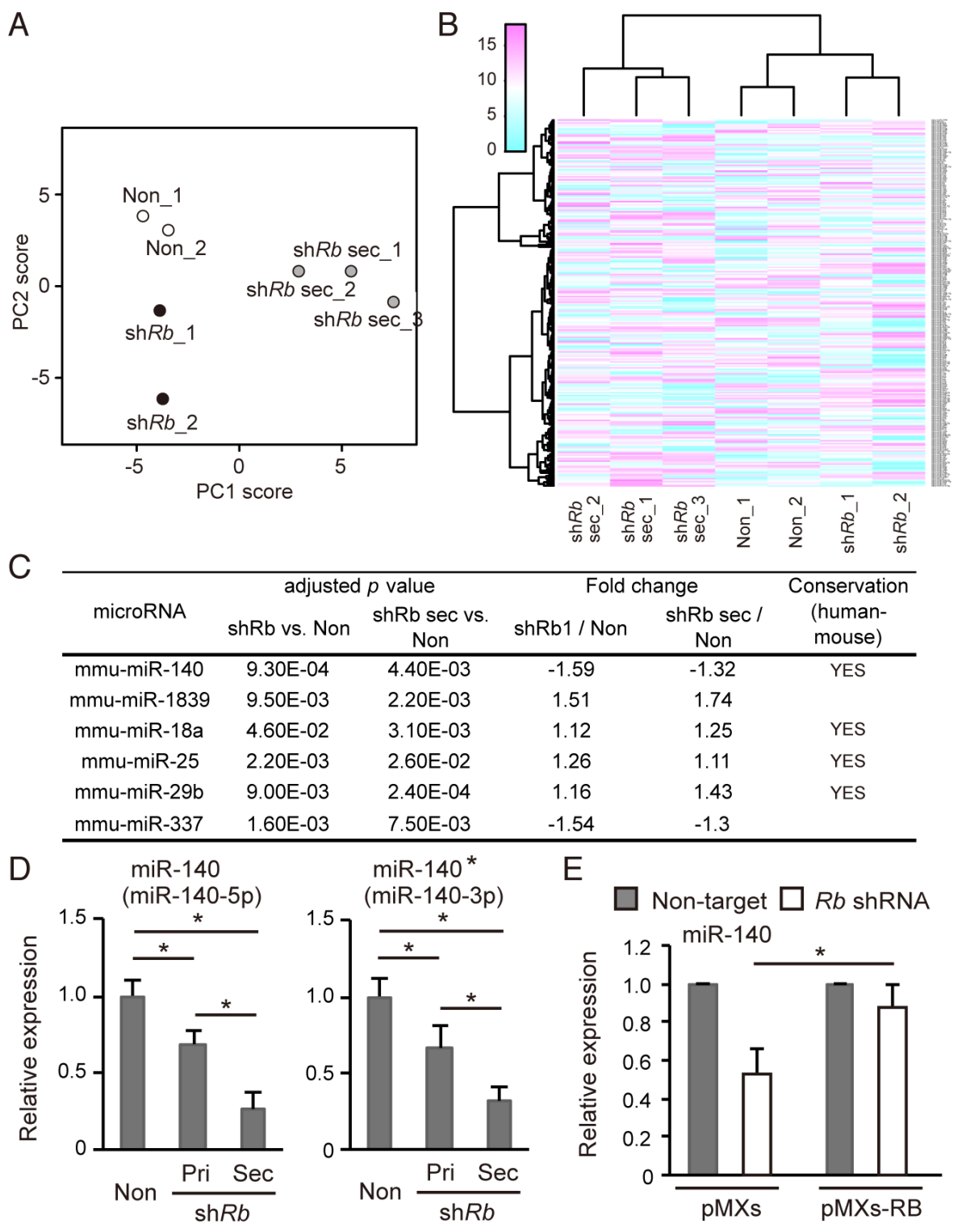

Figure 2: Rb depletion downregulates mir-140 expression. (A) Principal components analysis of normalized array data for 252 microRNAs. The scores of the first two principal components are shown. The proportions of variance for PC1 and PC2 were $54.4 \%$ and $23.0 \%$ respectively. (Cumulative proportion of PC1 and PC2 is $77.4 \%$ ). (B) Unsupervised hierarchical clustering of miRNA data for the 252 normalized miRNAs. Each column represents a sample, and each row represents the expression level of a miRNA. (C) The list of miRNAs differentially expressed depending on the Rb depletion status and the culture condition. The expression data of miRNA were analyzed by one-way ANOVA, and then by Dunnett's post-hoc test, and compared to control cells. Homology denotes the presence of homologous sequence in Homo sapiens and Mus musculus. (See Materials and Methods). (D) RT-qPCR of miR-140 (left) and miR-140* (right) in $p 53$-null soft tissue sarcoma cells transduced with the indicated vector. $N=3$. (E) RT-qPCR of miR-140 in $p 53$-null soft tissue sarcoma cells transduced with the indicated vector. $N=3$. 
breast cancer cell line. Since both RB and hsa-mir-140 are frequently downregulated in basal-like breast cancer cells $[20,23]$, which typically show elevated cytokine secretion [24], we focused on human breast cancers. As mentioned above, the human IL-6 gene has a hsa-mir-140 target sequence in its 3'UTR (Figure 6A). We observed that the upregulation of $I L-6$ abundance following RB-depletion in MCF-7 cells was significantly antagonized by hsa-mir-140 overexpression (Figure 6B and 6C); this finding was confirmed by ELISA technique (Figure 6D). In addition, hsa-mir-140 antagonized enhancement of sphere-forming activity induced by RB depletion (Figure 6E). Moreover, the addition of recombinant human IL-6 antagonized the inhibition of spherogenesis caused by hsa-mir-140 overexpression in a concentration-dependent manner (Figure 6F).

On the other hand, while RB depletion in MCF-7 cells downregulated hsa-miR-140 expression, overexpression of a constitutively active form RB (RB7LP) [25] significantly upregulated hsa-miR-140 expression (Figure 6G and 6H). Furthermore, we constructed luciferase reporter vectors carrying either a wild-type human IL-6-3'UTR ( $h I L-6$ $\left.3^{\prime} U T R-W T\right)$ or a mutated target sequence ( $h I L-6-3$ 'UTR-Mut) (Supplementary Figure 4A). We found that hsa-mir-140 overexpression significantly suppressed the activity of $h I L$ 6-3'UTR-WT but not hIL-6-3'UTR-Mut (Figure 6I). These results indicate that RB upregulates hsa-miR-140 expression, and that the hsa-mir-140-IL6 axis mediates RB function to suppress the self-renewal of human breast cancer cells.

\section{DISCUSSION}

The data presented here demonstrate that $\mathrm{Rb}$ inactivation dysregulates an miRNA signature, causing significant changes in mRNA expression. These signatures were determined in the context of acquiring self-renewal activity in p53-null mouse soft tissue sarcoma cells. We focused on mir-140 in particular because of the significant expression change and conservation between human and mouse. Moreover, hsa-mir-140 has been implicated in the suppression of a variety of human cancers, including breast cancer [16-20]. Combined with the information indicating the pivotal role of $\mathrm{RB}$ in the malignant progression of breast cancer [26-28], we anticipated a functional interaction between RB and hsa-mir-140. Previously, it was reported that p53, another well-known tumor suppressor, upregulates the transcription of tumorsuppressor miRNAs such as miR-34a/b/c/, miR-107, miR-145, miR-192, and miR-215, which regulate cell proliferation, apoptosis, and angiogenesis [29].

The induction of IL-6 secretion and subsequent autocrine/paracrine activation of STAT3 signaling supports the self-renewal activity of not only cancer cells $[24,30,31]$ but also embryonic stem cells or induced

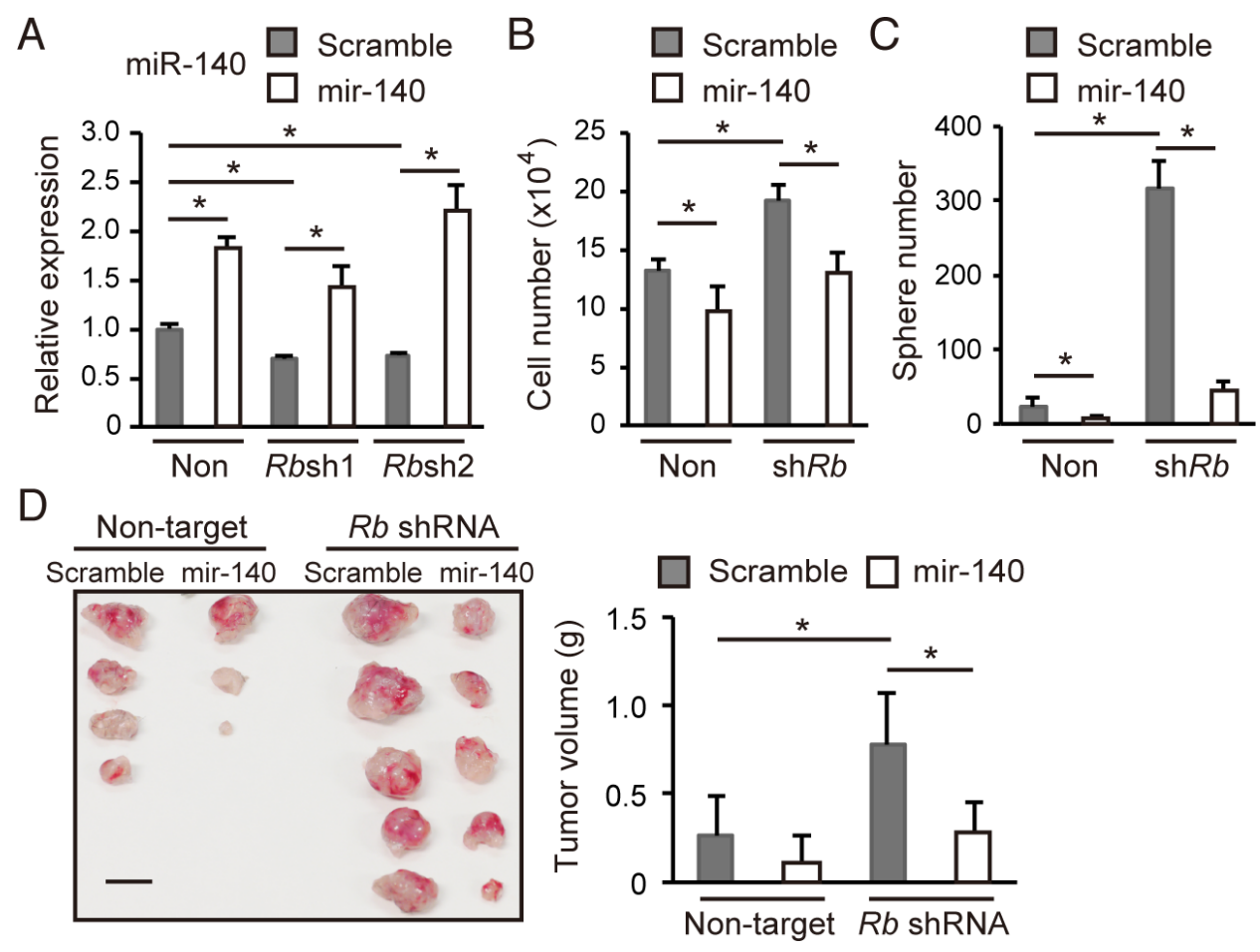

Figure 3: $\mathbf{m m u - m i r - 1 4 0}$ antagonizes the malignant features induced by Rb depletion. (A) RT-qPCR of mmu-miR-140 in $p 53$-null sarcoma cells transduced with the indicated vector. $N=3$. (B) Total cell numbers of $p 53$-null sarcoma cells transduced with the indicated vector after 72 hours culture. $N=3$. (C) The number of spheres derived from $5 \times 10^{4}$ of $p 53$-null soft tissue sarcoma cells transduced with the indicated vector. $N=3$. (D) Tumor initiation by $1 \times 10^{5}$ cells transduced with the indicated vector in C $57 \mathrm{BL} / 6 \mathrm{mice}$ (left; day 24). Scale bar: $10 \mathrm{~mm}$. Tumors were weighed (right). $N=5$. 
Table 1: Identification of the mir-140-target gene that contributes to $\mathrm{Rb}$ depletion-induced malignant phenotype

\begin{tabular}{ccccccc}
\hline \multirow{2}{*}{ Gene } & $\boldsymbol{a}$ value & $\boldsymbol{m}$ value & $\boldsymbol{q}$ value & rank & miR140 & miR140* \\
\hline Il6 & 10.4 & 2.6 & $9.83 \mathrm{E}-26$ & 1 & -0.15 & -0.64 \\
Itgb3 & 10.5 & 1.6 & $1.60 \mathrm{E}-10$ & 10 & N/A & -0.91 \\
Igfbp5 & 8.3 & 1.6 & $6.53 \mathrm{E}-03$ & 191 & -0.65 & N/A \\
Erlin2 & 10.8 & 0.7 & $1.19 \mathrm{E}-02$ & 232 & -0.15 & -0.90 \\
Vegfa & 13.0 & 0.6 & $1.52 \mathrm{E}-02$ & 258 & -0.82 & N/A \\
Lats 2 & 11.2 & 0.6 & $1.83 \mathrm{E}-02$ & 281 & -0.75 & N/A \\
Cd40 & 2.3 & 3.1 & $2.60 \mathrm{E}-02$ & 313 & N/A & -0.63 \\
Serpind1 & 7.4 & 1.5 & $2.65 \mathrm{E}-02$ & 315 & N/A & -0.99 \\
Slc2a1 & 11.0 & 0.6 & $2.91 \mathrm{E}-02$ & 330 & -0.61 & N/A \\
\hline
\end{tabular}

The genes listed here were upregulated by $\mathrm{Rb}$ depletion and possibly targeted by mmu-mir-140. These genes exhibited high mirSVR scores to miR-140 and/or miR-140*, and were sorted according to the $p$ value of their rpkm values. mirSVR scores were obtained from microRNA.org [51, 52]. The $q$ value represents adjusted $p$ value by using the BH method, the $a$ value represents the average expression level of triplicate samples, and the $m$ value represents fold change on $\log 2 \operatorname{scale}$.

A

\begin{tabular}{llll}
\hline GO Biological Process Term & $p$ value & Bonferroni & Benjamini \\
\hline \hline Immune response & $1.29 \mathrm{E}-07$ & $6.37 \mathrm{E}-01$ & $3.97 \mathrm{E}-01$ \\
Wnt receptor signaling pathway & $6.11 \mathrm{E}-04$ & $9.59 \mathrm{E}-01$ & $6.54 \mathrm{E}-01$ \\
Cell proliferation & $1.92 \mathrm{E}-03$ & $9.62 \mathrm{E}-01$ & $5.58 \mathrm{E}-01$ \\
\hline \hline GO Cellular Compartment Term & $p$ value & Bonferroni & Benjamini \\
\hline \hline Extracellular region part & $1.28 \mathrm{E}-03$ & $2.76 \mathrm{E}-01$ & $2.76 \mathrm{E}-01$ \\
Extracellular region & $4.77 \mathrm{E}-03$ & $7.00 \mathrm{E}-01$ & $4.52 \mathrm{E}-01$ \\
Proteinaceous extracellular matrix & $6.82 \mathrm{E}-03$ & $8.22 \mathrm{E}-01$ & $4.37 \mathrm{E}-01$ \\
\hline
\end{tabular}

C

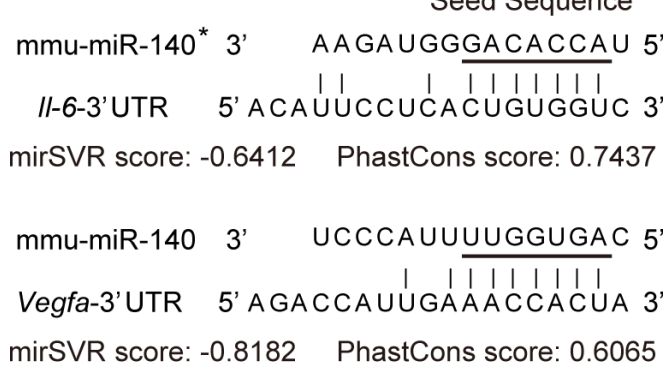
TPM (tags per million)

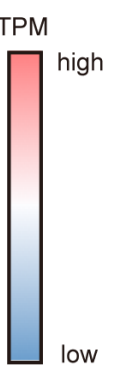

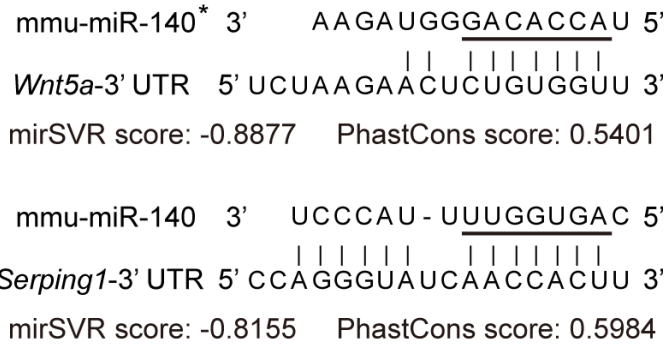

mirSVR score: -0.8155 PhastCons score: 0.5984

Figure 4: Identification of genes induced by Rb depletion in a mir-140-dependent manner. (A) The ontology of the top 3 gene sets influenced by Rb depletion possibly in an mir-140-dependent manner was determined by GO Biological Process provided by DAVID. (B) A heat map illustrating the expression levels of the indicated genes in p53-null soft tissue sarcoma cells transduced with the indicated vector. (C) The sequences of mouse Il-6, Vegfa, Wnt5a and Serping1 3'UTR corresponding to the seed sequence of mmu-mir-140 (underline) are presented with their mirSVR and PhastCons scores. 
pluripotent stem cells $[32,33]$. The inactivation of RB functions is known to enhance stem cell-like activities $[21,34,35]$. This work proposes that the RB-miR-140IL-6 axis may play a critical role in cancer stem cells. Our findings coincide with the recent finding that $h s a-$ mir-140 downregulation promotes cancer stem cell formation in breast cancer cells [20]. We however point out that miR-140 is not solely a mechanism that links RB to IL-6, since as compared to the mild effect of RB depletion on hsa-miR-140 expression in MCF-7 cells, IL-6 induction was more robust (Figure 6H and 6B). This suggests that multiple mechanisms are involved in RBIL-6 linkage, which we are currently investing (Kitajima et al., unpublished).

A limitation of this study is that we did not determine how RB upregulates miR-140 expression. Compared to the negative regulation of target genes by $\mathrm{RB}$, the mechanism of positive regulation by $\mathrm{RB}$ remains poorly understood. Both mmu-mir-140 and $h s a$ mir-140 are encoded in an intronic region of WWP2 gene encoding an E3 ubiquitin ligase. The transcription of these mir-140s is positively regulated by SOX family members including SOX5, 6 and 9; these SOX genes are negatively regulated through DNA methylation in their transcriptional regulatory regions $[20,36-38]$. We are currently testing the possibility that RB depletion promotes demethylation in their promoter regions.

In addition to $\mathrm{Il}-6$, the genes induced by $\mathrm{Rb}$ depletion possibly in a mir-140-dependent manner included those encoding various secreted proteins such as proteases, growth factors, cytokines, and chemokines (Table 1). GO analysis identified an enrichment of genes that are typically involved in immune responses and extracellular activities (Figure 4A). Among secreted protein genes, the 3 'UTR of $V E G F$ gene can be targeted by hsa-miR-140 [21], and reportedly $V E G F$ gene is induced by RB inactivation [39]. These facts may increase the authenticity of the genes listed in Figure 4B, which includes genes such as $\mathrm{Il}-11$, $H g f$, Vegfa, and Wnt5a, all of which are implicated in the malignant behavior of tumor cells [40-43]. Moreover, reportedly mir-140 expression is implicated in inflammatory disease. Inflammatory cytokines, including IL-1 $\beta$ and TNF- $\alpha$, downregulate mir-140 expression leading to the development of osteoarthritis, most likely due to accelerated inflammation and/or ADAMTS5 activation [44]. Because $\mathrm{RB}$ is prevalently inactivated by various oncogenic signals during the malignant progression of many types of cancers, mir-140 can potentially serve as a therapeutic tool for disrupting linkages of oncogenic signals to inflammatory responses, cell proliferation, or pro-angiogenic responses.
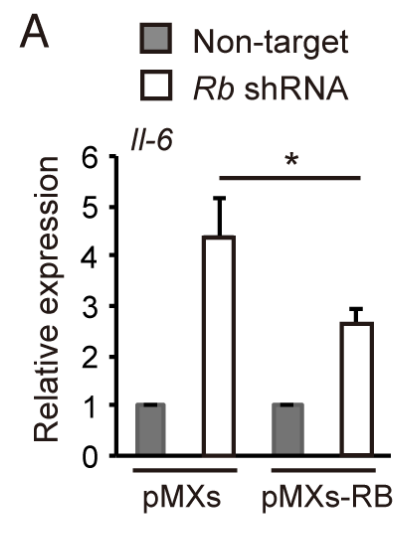

C
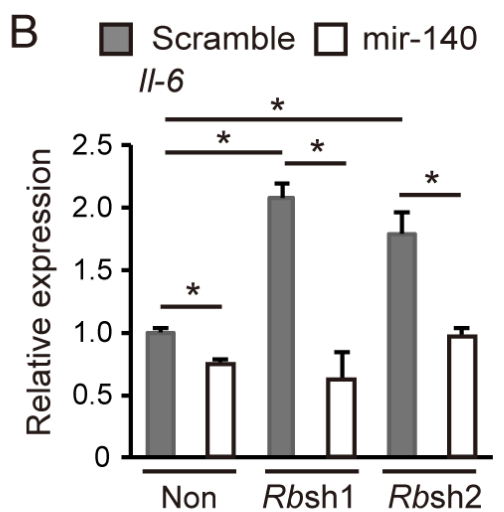

Seed Sequence

mIl-6-3' UTR WT 5' ACAUUCCUCACUGUGGUC 3' | | | | | | | mmu-miR-140* 3' . . AAGAUGGGACACCAU 5' mIl-6-3' UTR Mut 5' ACAUUCCUCACa a g u UC 3'

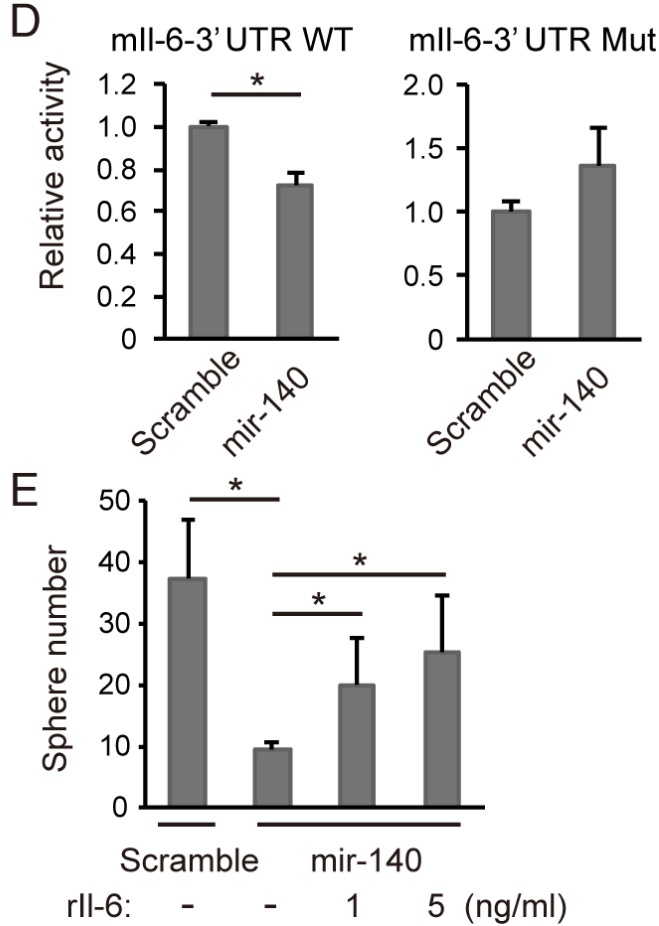

Figure 5: $\mathbf{m m u - m i r - 1 4 0}$ mediates Rb function to control $\mathbf{I l - 6}$ expression. (A) RT-qPCR of Il-6 in $p 53$-null soft tissue sarcoma cells transduced with the indicated shRNA and retroviral vectors. $N=3$. (B) RT-qPCR of $I l-6$ in $p 53$-null soft tissue sarcoma cells transduced with the indicated vectors. $N=3$. (C) The sequence of the mouse Il-6 3'UTR containing seed sequence of mmu-mir-140 (underlined). The seed sequence of the mouse Il-6 3'UTR was mutated as shown (mIl-6-3'UTR Mut). (D) mIl-6-3Times New RomanUTR WT or mIl-6-3'UTR Mut was transduced into NIH3T3 cells together with the mmu-mir-140 expression vector or control (scramble). After 48 hours, luciferase activity was measured. (E) Number of spheres derived from $5 \times 10^{4}$ of $p 53$-null soft tissue sarcoma cells transduced with the indicated vector in the presence of indicated concentration of recombinant mouse Il-6 (\#406-ML-005, R\&D Systems). $N=3$. 


\section{MATERIALS AND METHODS}

Mice

p53-knockout mice [45] were obtained from RIKEN BioResource Center (Ibaragi, Japan; \#CDB0001K). C57BL/6 mice were purchased from Japan SLC. Animals were handled in accordance with the animal welfare guidelines of the Kanazawa University.

\section{Primary cell culture}

Minced pieces of soft tissue sarcoma samples derived from $p 53$-knockout mice were digested with $300 \mathrm{U} / \mathrm{ml}$ collagenase, $100 \mathrm{U} / \mathrm{ml}$ hyaluronidase and $100 \mu \mathrm{g} / \mathrm{ml}$ DNase I in $\alpha$-modified Eagle's medium $(\alpha \mathrm{MEM})$ supplemented with $10 \%$ fetal bovine serum
(FBS). The resulting cells were maintained in aMEM supplemented with $10 \%$ FBS.

\section{Sphere formation assay}

Cells cultured under monolayer conditions were detached with trypsin-EDTA, and filtered through a $40 \mu \mathrm{m}$ cell strainer. The cells were then inoculated into $1 \%$ methylcellulose-containing serum-free aMEM supplemented with B27 (Life Technologies, Carlsbad, USA), $10 \mathrm{ng} / \mathrm{ml}$ human EGF (PeproTech, Rocky Hill, USA) and $10 \mathrm{ng} / \mathrm{ml}$ human bFGF (PeproTech), at a density of $5 \times 10^{3}$ cells per well on 6-well-type ultra-low attachment plate (EZ-BindShut II, AGC Techno Glass, Shizuoka, Japan). After 10-14 days incubation, spheres were observed with the assistance of an inverted phase contrast microscopy, and analyzed by BZ analysis software
A

C

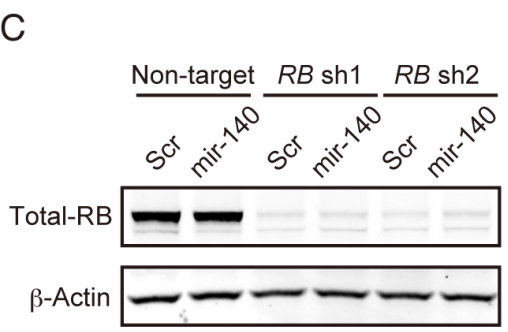

G

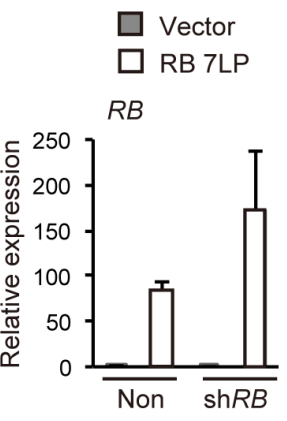

Seed Sequence

hsa-miR-140 3' UCCCAUUUUGGUGAC 5'

IL-6-3'UTR 5' UUUUAAGAAGUACCACUU 3'

mirSVR score: -0.1809 PhastCons score: 0.6938

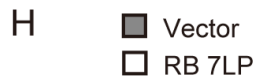

D

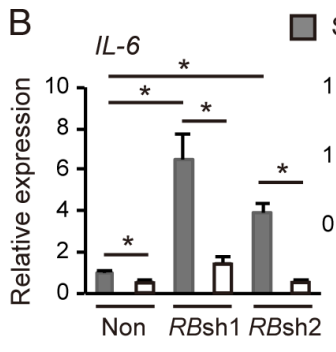

$\mathrm{E}$

Scramble $\square$ mir-140

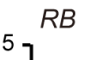

1.

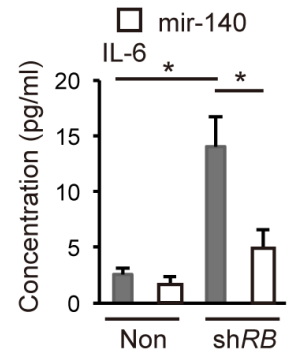

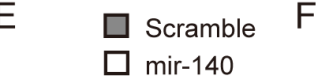

$\mathrm{F}$

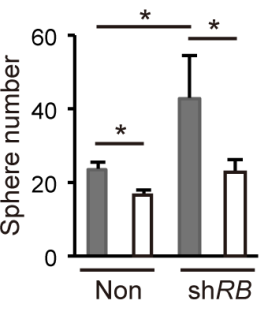

mir-140

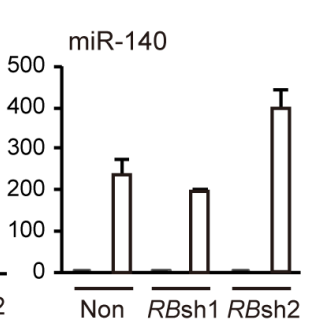

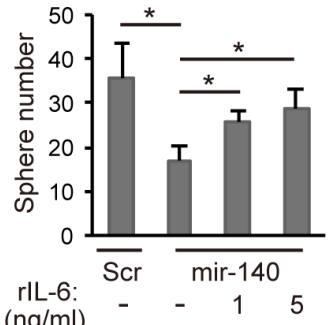

I hIL-6-3'UTR WT hIL-6-3'UTR Mut
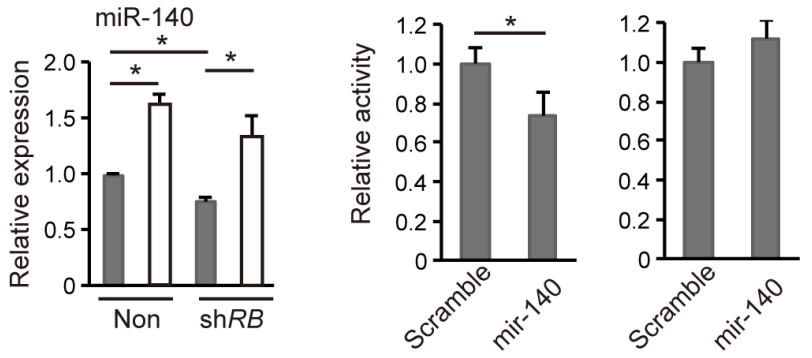

Figure 6: hsa-mir-140 suppresses $I L-6$ expression induced by RB depletion in human breast cancer cells. (A) The sequence of the human Il-6 3'UTR and the seed sequence of hsa-mir-140 (underlined) are indicated. mirSVR and Phantcons scores are indicated. (B) RT-qPCR of the indicated genes in MCF7 cells transduced with the indicated vector. $N=3$. (C) IB of the indicated proteins in MCF-7 cells transduced with the indicated vector. (D) ELISA of human IL-6 levels in MCF-7 cells transduced with the indicated vector following 8 hours culture. (E) Number of spheres derived from $1.25 \times 10^{3}$ of MCF-7 cells transduced with the indicated vectors. $N=3$. (F) Number of spheres derived from $1.25 \times 10^{3}$ of MCF-7 cells transduced with the indicated vector in the presence of indicated concentration of recombinant human IL-6 (\#206-IL-010, R\&D Systems). $N=3$. (G) RT-qPCR of RB7LP in MCF-7 cells transduced with the indicated vector. $N=3$. (H) RT-qPCR of hsa-miR-140 in MCF-7 cells transduced with the indicated vector. $N=3$. (I) $\mathrm{h} I L-6-3^{\prime} U T R=W T$ or hIL6-3'UTR Mut was transduced into MCF-7 cells together with the hsa-mir-140 expression vector or control (scramble). After 48 hours, luciferase activity was measured. 
on a BZ-9000 fluorescence microscope (Keyence, Osaka, Japan) using the Hybrid Cell Counting module. Sphereforming units were determined at a given day by counting cell aggregates with larger than 3,000 $\mu^{2}$ surface area and with the ratio of the longest diameter and the shortest diameter (L/S ratio) less than 1.5 (spherical figure). The whole area in a dish was scanned by automated microscope, and sphere number per dish was calculated from tiled image data.

\section{Establishment of secondary cells}

More than 10 spheres induced by $\mathrm{Rb}$ depletion were manually picked up by micropippette under the microscope, collected into a $15 \mathrm{ml}$ centrifuge tube, resuspended in $2 \mathrm{ml}$ of $10 \%$ FBS-containing $\alpha \mathrm{MEM}$, disaggregated with cell a 40- $\mu \mathrm{m}$ strainer, and plated onto a 2D culture dish. To establish control secondary cells, all tumor cells in the sphere culture were collected into a $15 \mathrm{ml}$ centrifuge tube after 2 weeks of culture, washed twice with $5 \mathrm{ml}$ of serum-free $\alpha \mathrm{MEM}$, resuspended in $2 \mathrm{ml} \mathrm{10 \%} \mathrm{FBS-containing} \alpha \mathrm{MEM}$, and then plated onto a 2D culture dish.

\section{Cell lines}

NIH3T3 cells (gifted from Dr. Makoto Noda, Kyoto University) and MCF-7 cells (RIKEN BRC, RCB1904) were cultured in Dulbecco's modified Eagle's medium (DMEM) containing 10\% FBS.

\section{Generation of lentivirus}

MISSION TRC validated shRNA target sets for mouse Rb (\#1:TRCN0000042543, \#2: TRCN0000042544), human $R B$ (\#1TRCN0000040163, \#2: TRCN0000010419) and negative control (SHC002) were purchased from Sigma-Aldrich (Missouri, USA). Murine microRNA precursor constructs for mmu-mir-140 (MMIR-140-PA-1) and mouse precursor scramble negative control (MMIR000-PA-1) were purchased from System Biosciences (Mountain View, USA). Generation and infection of lentivirus were performed according to the manufacturer's instruction. pQCXIH-PSM-RB7LP was purchased from Addgene (\#37106). RB7LP lacking stop codon was amplified by PCR using primers attB1-7LP (GGGGAC AAGTTTGTACAAAAAAGCAGGCTTCGCCACCAT GAACACTATCCAACA) and attB2-7LP (GGGGACCAC TTTGTACAAGAAAGCTGGGTTTTTCTCTTCCTTG TTTGAGGTATCCA). PCR products was cloned into pDONR223, sequenced by ABI 3130 sequencer, and then subcloned into pLenti6.3/V5-DEST.

\section{Quantitative RT-PCR (RT-qPCR)}

Total RNA was extracted by using a miRNeasy Mini Kit (Qiagen). Reverse transcription was performed by using TaqMan MicroRNA Reverse Transcription Kit (Applied Biosystems, Foster City, USA), and realtime PCR quantitation was performed by using TaqMan Universal Master Mix II (Applied Biosystems) with LightCycler 480 System II (Roche, Basel, Switzerland), according to the manufacturer's instructions. To measure mRNA, total RNA was extracted by using TRIzol (\#15596018, Life Technologies), reverse-transcribed using High Capacity RNA-to-cDNA Kit (Applied Biosystems), and quantitated using TaqMan Gene Expression Master Mix (Applied Biosystems), according to the manufacturer's instructions. The TaqMan probes used were mmu-miR-140, hsa-miR-140-3p, snoRNA202, RNU48, Il6, IL6, Rb1, RB1, Actb and ACTB (Applied Biosystems, assay ID 001187, 002234, 001232, 001006, Mm00446190_m1, Hs00985639_m1, Mm00485586_m1, Hs01078066_m1, Mm00607939_s1 and Hs99999903_ m1). snoRNĀ202, RNU48, Actb and $A C T B$ were used as internal controls.

\section{Immunoblotting (IB)}

Whole-cell and nuclear fractions were prepared as described previously [46]. IB was conducted as described previously [46] using the following antibodies to: Phospho-Rb (\#9308, Cell Signaling Technology), Total RB (\#554136, BD Biosciences), Cyclin D1 (\#2926, Cell Signaling Technology), $\alpha$-Tubulin (\#CP06, Calbiochem) and $\beta$-Actin (\#3700, Cell Signaling Technology).

\section{RNA sequencing}

The total RNA was extracted using the TRIzol reagent (\#15596018, Life Technologies). From $15 \mu \mathrm{g}$ of total RNA, a RNA-sequence library was constructed using the mRNA-sequence Sample Preparation Kit, according to the manufacturer's instructions (Illumina, California, USA). A HiSeq 2000 sequencer was used to generate 36bp single-end-read RNA sequence tags according to the manufacturer $>$ s protocol. The RNA-sequence tags were mapped to the mouse genomic sequence ( $\mathrm{mm} 9$ from the UCSC Genome Browser) using the ELAND program (Illumina). Unmapped or redundantly mapped sequences were removed from the dataset, and only uniquely mapped sequences without any mismatches were used for analyses [47]. The raw data of RNA sequence are available in DNA Data Bank of Japan (DDBJ) (DRA002910 and DRA002911).

\section{In vivo tumor formation assay}

Cells were suspended $\left(1 \times 10^{5}\right.$ cells/sample $)$ in $50 \mu \mathrm{l} \alpha \mathrm{MEM}$ with $10 \% \mathrm{FBS}$ and $50 \mu \mathrm{l}$ Matrigel (BD Biosciences), and then they were injected subcutaneously into C57BL/6 male mice. After 24 days, the mice were sacrificed for separating tumors, and tumors were separated and weighed. 


\section{miRNA microarray}

Total RNA was extracted by using the miRNeasy Mini Kit (Qiagen, Tokyo, Japan). The quality of the RNA samples was assessed using the Agilent 2100 Bioanalyzer 2100 (Agilent, Santa Clara, USA). The microRNA microarray analysis was performed with a Mouse miRNA microarray $8 \times 15 \mathrm{~K}$ Rel. 15.0 (Agilent, \#29152). The fluorescence intensity was measured with a G2505B Micro Array Scanner (Agilent) in the Institute for Gene Research, Kanazawa University (Ishikawa, Japan). The data were normalized using the quantile method with GeneSpring 12.6.1 GX software (Agilent). The raw data are available in the Gene Expression Omnibus (GEO) (GSE77222).

\section{Determination of miRNAs regulated by $\mathbf{R b}$}

miRNA microarray data were analyzed using oneway ANOVA of the three groups regarding 252 miRNAs, in which the false discovery rate (FDR) was controlled with the Benjamini-Hochberg $(\mathrm{BH})$ procedure. The 37 miRNAs with an adjusted $p$ value $<0.1$ were subjected in succession to Dunnett's test using the control sample group as a control. Those miRNAs that had less than 0.05 of the adjusted $p$ value in both comparisons of $R b$ shRNA vs. Non-target and $R b$ shRNA secondary vs. non-target, and where both comparisons of altered expression with in agreement (up- or down-regulation), were regarded as candidate miRNAs regulated by $\mathrm{Rb}$.

\section{Generation of retroviruses}

Retroviruses were recovered from the Platinum-E retroviral packaging cell line gifted from Dr. Toshio Kitamura (The Institute of Medical Science, The University of Tokyo). Platinum-E cells were maintained in DMEM supplemented with $10 \%$ FBS, and transfected with pMXs or pMXs- human RB. For retrovirus production, $6 \times 10^{6}$ Platinum-E cells were transfected with $10 \mu \mathrm{g}$ of each pMXs vector in $46 \mathrm{mg} / \mathrm{ml}$ polyethyleneimine. After 48 hours, the medium containing retrovirus particles was collected, passed through a $0.45 \mu \mathrm{m}$ filter, and concentrated using polyethylene glycol.

\section{Determination of genes regulated by $\mathrm{Rb}$}

The tag count data from the RNA sequencing analysis were normalized by the iDEGES/edgeR method. Differentially Expressed Genes (DEGs) were estimated using the edgeR method to determine the genes that had an FDR threshold of 5\% as DEGs. These analyses were computed in the 'TCC' package by using R 3.1.0 [48].

\section{Reporter assay}

For the 3'UTR reporter assay, the 3' UTR of mouse Il-6 and human IL-6 were amplified by PCR from mouse cDNA.
The resulting fragment was inserted into the pmirGLO vector (Promega Corporation, Madison, USA), to generate a luciferase reporter construct $I L-6-3^{\prime} U T R$ according to the manufacturer's instructions. We also mutated complementary seed sequences in the miR-140-binding region (See Figure 4B and Supplementary Figure 4A), and generated the reporter construct Il-6-3'UTR Mut. NIH3T3 cells were transfected with $0.5 \mu \mathrm{g}$ reporter construct, either $3.0 \mu \mathrm{g}$ mmu-miR-140 construct or $3.0 \mu \mathrm{g}$ scramble control construct, and $0.25 \mu \mathrm{g}$ $\beta$-galactosidase using $100 \mu \mathrm{l}$ Opti-MEM (Life Technologies) and 11.25 $\mu \mathrm{l}$ FuGENE6 (Promega Corporation, Cat. \#E2691) in 6-well-type plates according to the recommended protocol. At 48 hours post transfection, luciferase activity was assessed using $1 \mathrm{mM}$ D-luciferin potassium salt. Luciferase activity was normalized using $\beta$-galactosidase. MCF-7 cells were transfected with $0.05 \mu \mathrm{g}$ reporter construct and either $0.3 \mu \mathrm{g}$ hsa-miR-140 construct or $0.3 \mu \mathrm{g}$ scramble control construct using $10 \mu \mathrm{l}$ Opti-MEM (Life Technologies, Cat. \#31985700 ) and 1.2 $\mu$ l FuGENE6 in 96-well-type plates according to the recommended protocol. At 24 hours post transfection, luciferase activity was assessed using Dual-Glo Luciferase assay system (Promega Corporation, Cat. \#E2920).

\section{Cap analysis gene expression (CAGE) sequencing}

RNA was extracted using a miRNeasy Mini Kit (Qiagen). RNA quality was assessed by Bioanalyzer (Agilent) and standardized with an RNA integrity number (RIN) > 7.0. RNA purity was analyzed by Nano Drop and considered good-quality when A260/280 and A260/230 ratios were $>1.7$. First strand cDNAs were transcribed to the 5' end of capped RNAs, attached to CAGE "bar code" tags (Supplementary Table 2) and the sequenced CAGE tags were mapped to the mouse $\mathrm{mm} 9$ genomes using BWA software (v0.5.9) after discarding ribosomal or non- $\mathrm{A} / \mathrm{C} /$ G/T base-containing RNAs. For tag clustering, CAGEtag 5' coordinates were input for Reclu clustering, with a maxmum irreproducible discovery rate of (IDR) 0.1 and minimum tags per million (TPM) value of $0.1[49,50]$

\section{Determination of mir-140-dependent $\mathrm{Rb}$ inactivation signature}

Genes were filtered into the $\mathrm{Rb}$ inactivation signature if their TPM were: 1) > 1.0 in scramble miRNAoverexpressed and $\mathrm{Rb}$-depleted cells, and 2) $>1.5$ times higher in either miRNA-overexpressed or Rb-depleted cells than in control cells. From that subset genes, genes with decreased expression in mir-140-overexpressed and RB-depleted cells compared with scramble miRNAoverexpressed and Rb-depleted cells were identified, 412 genes total.

\section{Statistical analysis}

Statistical significance was assessed using unpaired two-tailed Student's $t$-test (indicated by horizontal and 
vertical bars) or one-way ANOVA followed by Tukey's post-hoc test (indicated by horizontal bars). $p$ values less than 0.05 were considered significant as denoted by an asterisk $(*)$. Data were presented as mean \pm standard deviation (S.D.). In one-way ANOVA followed by Tukey's post-hoc tests, only pairs of our interest to the study were indicated.

\section{ACKNOWLEDGMENTS}

This work was supported by Funding Program for Next Generation World-Leading Researchers to CT, Grant-in-Aid for Scientific Research to CT (26290037, 26640070, 5H01487) and SK (25830077, 23701048), Astellas Foundation for Research on Metabolic Disorders, Takeda Science Foundation, Naito Foundation, DaiichiSankyo Foundation for Life Science, Hokkoku Foundation for Cancer Research and IMSUT Joint Research Project to CT, and Hokuriku Bank Research Grant for Young Scientists to SK.

\section{CONFLICTS OF INTEREST}

The authors declare no conflicts of interest.

\section{Authors' contributions}

Akiyo Yoshida conceived experiments, generated and analyzed data, and wrote the manuscript; Shunsuke Kitajima conceived experiments, generated and analyzed data, and wrote the manuscript; Fengkai Li generated data; Chaoyang Cheng generated data; Yujiro Takegami generated and analyzed data; Naoyuki Hayashi constructed plasmids; Yuuki Nishimoto generated data; Naoko Nagatani generated data; Susumu Kohno generated data; Hayato Muranaka generated data; Takumi Nishiuchi generated data; Sawako Suzuki generated data; Shinji Nakao provided advice; Tomoaki Tanaka generated data; Osamu Hirose provided advice; and Chiaki Takahashi supervised the research and wrote the manuscript.

\section{REFERENCES}

1. Ha M, Kim VN. Regulation of microRNA biogenesis. Nat Rev Mol Cell Biol. 2014; 15:509-524.

2. Winter J, Jung S, Keller S, Gregory RI, Diederichs S. Many roads to maturity: microRNA biogenesis pathways and their regulation. Nat Cell Biol. 2009; 11:228-234.

3. Esquela-Kerscher A, Slack FJ. Oncomirs - microRNAs with a role in cancer. Nat Rev Cancer. 2006; 6:259-269.

4. Lin S, Gregory RI. MicroRNA biogenesis pathways in cancer. Nat Rev Cancer. 2015; 15:321-333.

5. Valastyan S, Weinberg RA. MicroRNAs: Crucial multitasking components in the complex circuitry of tumor metastasis. Cell Cycle. 2009; 8:3506-3512.
6. Lu J, Getz G, Miska EA, Alvarez-Saavedra E, Lamb J, Peck D, Sweet-Cordero A, Ebert BL, Mak RH, Ferrando AA, Downing JR, Jacks T, Horvitz HR, et al. MicroRNA expression profiles classify human cancers. Nature. 2005; 435:834-838.

7. Thomson JM, Newman M, Parker JS, Morin-Kensicki EM, Wright T, Hammond SM. Extensive post-transcriptional regulation of microRNAs and its implications for cancer. Genes Dev. 2006; 20:2202-2207.

8. Merritt WM, Lin YG, Han LY, Kamat AA, Spannuth WA, Schmandt R, Urbauer D, Pennacchio LA, Cheng JF, Nick AM, Deavers MT, Mourad-Zeidan A, Wang H, et al. Dicer, Drosha, and outcomes in patients with ovarian cancer. N Engl J Med. 2008; 359:2641-2650.

9. Lin RJ, Lin YC, Chen J, Kuo HH, Chen YY, Diccianni MB, London WB, Chang CH, Yu AL. microRNA signature and expression of Dicer and Drosha can predict prognosis and delineate risk groups in neuroblastoma. Cancer Res. 2010; 70:7841-7850.

10. Khoshnaw SM, Rakha EA, Abdel-Fatah TM, Nolan CC, Hodi Z, Macmillan DR, Ellis IO, Green AR. Loss of Dicer expression is associated with breast cancer progression and recurrence. Breast Cancer Res Treat. 2012; 135:403-413.

11. Kumar MS, Lu J, Mercer KL, Golub TR, Jacks T. Impaired microRNA processing enhances cellular transformation and tumorigenesis. Nat Genet. 2007; 39:673-677.

12. Chan JA, Krichevsky AM, Kosik KS. MicroRNA-21 is an antiapoptotic factor in human glioblastoma cells. Cancer Res. 2005; 65:6029-6033.

13. Gregory PA, Bracken CP, Bert AG, Goodall GJ. MicroRNAs as regulators of epithelial-mesenchymal transition. Cell Cycle. 2008; 7:3112-3118.

14. Blandino G, Fazi F, Donzelli S, Kedmi M, Sas-Chen A, Muti P, Strano S, Yarden Y. Tumor suppressor microRNAs: a novel non-coding alliance against cancer. FEBS Lett. 2014; 588:2639-2652.

15. Takahashi C, Sasaki N, Kitajima S. Twists in views on RB functions in cellular signaling, metabolism and stem cells. Cancer Sci. 2012; 103:1182-1188.

16. Yang H, Fang F, Chang R, Yang L. MicroRNA-140-5p suppresses tumor growth and metastasis by targeting transforming growth factor beta receptor 1 and fibroblast growth factor 9 in hepatocellular carcinoma. Hepatology. 2013; 58:205-217.

17. Yuan Y, Shen Y, Xue L, Fan H. miR-140 suppresses tumor growth and metastasis of non-small cell lung cancer by targeting insulin-like growth factor 1 receptor. PLoS One. 2013; 8:e73604.

18. Zhang W, Zou C, Pan L, Xu Y, Qi W, Ma G, Hou Y, Jiang P. MicroRNA-140-5p inhibits the progression of colorectal cancer by targeting VEGFA. Cell Physiol Biochem. 2015; 37:1123-1133.

19. Lan H, Chen W, He G, Yang S. miR-140-5p inhibits ovarian cancer growth partially by repression of PDGFRA. Biomed Pharmacother. 2015; 75:117-122. 
20. Li Q, Yao Y, Eades G, Liu Z, Zhang Y, Zhou Q. Downregulation of miR-140 promotes cancer stem cell formation in basal-like early stage breast cancer. Oncogene. 2014; 33:2589-2600.

21. Kitajima S, Kohno S, Kondoh A, Sasaki N, Nishimoto Y, Li F, Abdallah Mohammed MS, Muranaka H, Nagatani N, Suzuki M, Kido Y, Takahashi C. Undifferentiated State Induced by Rb-p53 Double Inactivation in Mouse Thyroid Neuroendocrine Cells and Embryonic Fibroblasts. Stem Cells. 2015; 33:1657-1669.

22. Salah M, Nishimoto Y, Kohno S, Kondoh A, Kitajima S, Muranaka H, Nishiuchi T, Ibrahim A, Yoshida A, Takahashi C. An in vitro system to characterize prostate cancer progression identified signaling required for self-renewal. Mol Carcinog. 2015.

23. Gauthier ML, Berman HK, Miller C, Kozakeiwicz K, Chew K, Moore D, Rabban J, Chen YY, Kerlikowske K, Tlsty TD. Abrogated response to cellular stress identifies DCIS associated with subsequent tumor events and defines basal-like breast tumors. Cancer Cell. 2007; 12:479-491.

24. Marotta LL, Almendro V, Marusyk A, Shipitsin M, Schemme J, Walker SR, Bloushtain-Qimron N, Kim JJ, Choudhury SA, Maruyama R, Wu Z, Gonen M, Mulvey LA, et al. The JAK2/STAT3 signaling pathway is required for growth of CD44(+)CD24(-) stem cell-like breast cancer cells in human tumors. The Journal of clinical investigation. 2011; 121:2723-2735.

25. Knudsen ES, Wang JY. Dual mechanisms for the inhibition of E2F binding to RB by cyclin-dependent kinase-mediated RB phosphorylation. Mol Cell Biol. 1997; 17:5771-5783.

26. Arima Y, Inoue Y, Shibata T, Hayashi H, Nagano O, Saya H, Taya Y. Rb depletion results in deregulation of E-cadherin and induction of cellular phenotypic changes that are characteristic of the epithelial-to-mesenchymal transition. Cancer Res. 2008; 68:5104-5112.

27. Bosco EE, Wang Y, Xu H, Zilfou JT, Knudsen KE, Aronow BJ, Lowe SW, Knudsen ES. The retinoblastoma tumor suppressor modifies the therapeutic response of breast cancer. The Journal of clinical investigation. 2007; 117:218-228.

28. Nik-Zainal S, Davies H, Staaf J, Ramakrishna M, Glodzik D, Zou X, Martincorena I, Alexandrov LB, Martin S, Wedge DC, Van Loo P, Ju YS, Smid M, et al. Landscape of somatic mutations in 560 breast cancer whole-genome sequences. Nature. 2016; 534:47-54.

29. Hermeking H. MicroRNAs in the p53 network: micromanagement of tumour suppression. Nat Rev Cancer. 2012; 12:613-626.

30. Korkaya H, Kim GI, Davis A, Malik F, Henry NL, Ithimakin S, Quraishi AA, Tawakkol N, D'Angelo R, Paulson AK, Chung S, Luther T, Paholak HJ, et al. Activation of an IL6 inflammatory loop mediates trastuzumab resistance in HER2+ breast cancer by expanding the cancer stem cell population. Molecular cell. 2012; 47:570-584.
31. Sansone P, Storci G, Tavolari S, Guarnieri T, Giovannini C, Taffurelli M, Ceccarelli C, Santini D, Paterini P, Marcu KB, Chieco P, Bonafe M. IL-6 triggers malignant features in mammospheres from human ductal breast carcinoma and normal mammary gland. The Journal of clinical investigation. 2007; 117:3988-4002.

32. Brady JJ, Li M, Suthram S, Jiang H, Wong WH, Blau HM. Early role for IL-6 signalling during generation of induced pluripotent stem cells revealed by heterokaryon RNA-Seq. Nat Cell Biol. 2013; 15:1244-1252.

33. Takahashi K, Yamanaka S. A decade of transcription factormediated reprogramming to pluripotency. Nat Rev Mol Cell Biol. 2016; 17:183-193.

34. Kareta MS, Gorges LL, Hafeez S, Benayoun BA, Marro S, Zmoos AF, Cecchini MJ, Spacek D, Batista LF, O'Brien $\mathrm{M}, \mathrm{Ng}$ YH, Ang CE, Vaka D, et al. Inhibition of pluripotency networks by the rb tumor suppressor restricts reprogramming and tumorigenesis. Cell stem cell. 2015; 16:39-50.

35. Kohno S, Kitajima S, Sasaki N, Takahashi C. Retinoblastoma tumor suppressor functions shared by stem cell and cancer cell strategies. World J Stem Cells. 2016; 8:170-184.

36. Yamashita S, Miyaki S, Kato Y, Yokoyama S, Sato T, Barrionuevo F, Akiyama H, Scherer G, Takada S, Asahara H. L-Sox 5 and Sox6 proteins enhance chondrogenic miR140 microRNA expression by strengthening dimeric Sox 9 activity. J Biol Chem. 2012; 287:22206-22215.

37. Nakamura $Y$, He X, Kato H, Wakitani S, Kobayashi T, Watanabe S, Iida A, Tahara H, Warman ML, Watanapokasin R, Postlethwait JH. Sox9 is upstream of microRNA-140 in cartilage. Appl Biochem Biotechnol. 2012; 166:64-71.

38. Yang J, Qin S, Yi C, Ma G, Zhu H, Zhou W, Xiong Y, Zhu X, Wang Y, He L, Guo X. MiR-140 is co-expressed with Wwp2-C transcript and activated by Sox9 to target Sp1 in maintaining the chondrocyte proliferation. FEBS Lett. 2011; 585:2992-2997.

39. Gabellini C, Del Bufalo D, Zupi G. Involvement of RB gene family in tumor angiogenesis. Oncogene. 2006; 25 : 5326-5332.

40. Yu H, Lee H, Herrmann A, Buettner R, Jove R. Revisiting STAT3 signalling in cancer: new and unexpected biological functions. Nat Rev Cancer. 2014; 14:736-746.

41. Gherardi E, Birchmeier W, Birchmeier C, Vande Woude G. Targeting MET in cancer: rationale and progress. Nat Rev Cancer. 2012; 12:89-103.

42. Goel HL, Mercurio AM. VEGF targets the tumour cell. Nat Rev Cancer. 2013; 13:871-882.

43. Anastas JN, Moon RT. WNT signalling pathways as therapeutic targets in cancer. Nat Rev Cancer. 2013; 13:11-26.

44. Miyaki S, Asahara H. Macro view of microRNA function in osteoarthritis. Nat Rev Rheumatol. 2012; 8:543-552.

45. Tsukada T, Tomooka Y, Takai S, Ueda Y, Nishikawa S, Yagi T, Tokunaga T, Takeda N, Suda Y, Abe S, et al. 
Enhanced proliferative potential in culture of cells from p53-deficient mice. Oncogene. 1993; 8:3313-3322.

46. Kitajima S, Miki T, Takegami Y, Kido Y, Noda M, Hara E, Shamma A, Takahashi C. Reversion-inducing cysteine-rich protein with Kazal motifs interferes with epidermal growth factor receptor signaling. Oncogene. 2011; 30:737-750.

47. Kanai A, Suzuki K, Tanimoto K, Mizushima-Sugano J, Suzuki Y, Sugano S. Characterization of STAT6 target genes in human B cells and lung epithelial cells. DNA research. 2011; 18:379-392.

48. Sun J, Nishiyama T, Shimizu K, Kadota K. TCC: an $\mathrm{R}$ package for comparing tag count data with robust normalization strategies. BMC Bioinformatics. 2013; 14:219.

49. Murata M, Nishiyori-Sueki H, Kojima-Ishiyama M, Carninci P, Hayashizaki Y, Itoh M. Detecting expressed genes using CAGE. Methods Mol Biol. 2014; 1164:67-85.
50. Ohmiya H, Vitezic M, Frith MC, Itoh M, Carninci P, Forrest AR, Hayashizaki Y, Lassmann T, Consortium F. RECLU: a pipeline to discover reproducible transcriptional start sites and their alternative regulation using capped analysis of gene expression (CAGE). BMC Genomics. 2014; 15:269.

51. Betel D, Koppal A, Agius P, Sander C, Leslie C. Comprehensive modeling of microRNA targets predicts functional non-conserved and non-canonical sites. Genome Biol. 2010; 11:R90.

52. Betel D, Wilson M, Gabow A, Marks DS, Sander C. The microRNA.org resource: targets and expression. Nucleic Acids Res. 2008; 36:D149-153. 